Proceedings

\title{
Chiroptical behavior of BINOL-based spiranic $O$-BODIPYs. A study on the influence of the structural factors.
}

\author{
Josué Jiménez, Esther M. Sánchez-Carnerero, Florencio Moreno, Antonia R. Agarrabeitia, María J. \\ Ortiz, Beatriz L. Maroto* and Santiago de la Moya* \\ Departamento de Química Orgánica I. Facultad de Ciencias Químicas. Universidad Complutense de \\ Madrid. Ciudad Universitaria s/n, 28040 Madrid, Spain. \\ * Correspondence: belora@ucm.es, santmoya@ucm.es; Tel.: +34-913945155, +34-913945090 \\ + Presented at The 21st International Electronic Conference on Synthetic Organic Chemistry. 1-30 November \\ 2017.
}

Academic Editor: name

Received: date; Accepted: date; Published: date

\begin{abstract}
Spiranic O-BODIPYs bearing a phenol-based bi(polyarene) unit tethered to the boron center through oxygen atoms constitute an interesting family of BINOL-BODIPY dyads useful for the development of photonic applications due to their synthetic accessibility and tunable photonic properties. In this communication, a preliminary study on the influence of the structure of both the BODIPY chromophore and the bi(polyarene) moiety over the chiroptical properties of this family of O-BODIPYs is carried out, directed to the improvement of said properties for their use in chiroptic applications.
\end{abstract}

Keywords: Organic Dyes, BODIPYs, Chiroptics, Circular dichroism

\section{Introduction}

Circular polarization confers to a beam of light a chiral character, due to the axial chirality associated to the corresponding (left or right) propagation mode. This chiral characteristic is the basis of the chiral photonics or chiroptics [1]. The differential absorption of right and left circularly polarized light by chiral non-racemic luminescent systems (molecules, ionic pairs, polymers, metal complexes, supramolecular aggregates, etc.) is known as circular dichroism (CD) [2]. CD can be evaluated by the Kunh's dissymmetry ratio, or absorption dissymmetry factor, $g_{a b s}$ [3], whose values stand between -2 and +2 (completely right and left polarized absorption, respectively). Analogously, circularly polarized luminescence (CPL) is the differential emission of right- and left-circularly polarized light by chiral luminescence systems, and it is quantified by the luminescence dissymmetry factor, glum (values between -2 and +2 ) [4].

CPL can be used as a source of information on the structure of the involved excited states. Within photonics, CPL is interesting for the improvement and potential development of multiple photonic tools, such as display devices including 3D optical displays, optical storage and processing systems, spintronics-based devices, biological probes and signatures, security tags, CPL lasers, enantioselective CPL sensors, or light-emission systems for asymmetric photosynthesis. Additionally, the omnipresence of chirality in the world around us (especially in the living world) makes CPL a valuable source of information on chiral environments to be exploited; e.g., by the future development of CPL microscopes [5].

The highest levels of CPL have been mainly achieved from chiral lanthanide complexes $[1 \mathrm{~d}, 5 \mathrm{e}, 6]$. However, their emission efficiencies are usually small, which hinders their use in certain CPL applications (e.g., in CPL lasing). Some purely organic molecules afford smaller CPL levels when they are hierarchically self-organized into non-racemic helical polymers or supramolecular 
aggregates [7]. Unfortunately, this organization has usually a negative influence in the emission efficiency. In contrast, simple (small, non-aggregated, non-polymeric) chiral organic molecules (SOM) enabling CPL are rare, and exhibit much smaller levels of CPL (typical $\left|g_{\text {lum }}\right|=10^{-5}-10^{-2}$ ) [8], being the structural diversity of the acting chromophores very poor [9].

In SOMSs, CD and CPL are closely related to the helical character of the molecule. Thus, configurationally labile $\pi$-conjugated helical molecules, such as bridged biphenyls or trityl propellers, have found a valuable application as chiroptical probes for the detection and quantification of enantiomers (CD-based chiral sensing) [10]. Additionally, the use of CD is the best way to investigate the formation of helices with induction of axial chirality $[11,2 c]$ and can be also used to predict whether the molecule would exhibit CPL or not.

4,4-Difluoro-4-bora-3a,4a-diaza-s-indacenes (F-BODIPYs) constitute a recognized family of fluorophores with noticeable utility in the development of photonic tools [12]. This is due to the excellent physical and chemical properties of the BODIPY chomophore, such as high solubility in organic-solvent systems improving dyed-material processability (e.g., in the preparation of organic films) or possibility of easy selective chemical functionalization to finely modulate the dye photophysical properties [12a-c]. These properties, joined to the usually large molar-absorption coefficients $(\varepsilon)$ and high fluorescence quantum yields $(\phi)$ of BODIPYs have promoted their application as fluorescent dyes for bioimaging, chemosensing and lasing, among other interesting photonic applications [12,13].

The chemical versatility of BODIPYs comes from the possibility of functionalizing selectively all the BODIPY positions, not only in the dipyrrin core, but also at boron by introducing pendant groups different from fluorine. This last strategy has been used to increase the dye stability against reactive singlet oxygen for lasing purposes [14], to enhance the dye solubility in water [15], to develop multichromophoric molecular cassettes endowed with efficient intramolecular excitation energy transfer (EET) [16] or to infer chiroptical activity to the BODIPY chromophore [16f,17].

Among the BODIPYs substituted at boron, those bearing a phenol-based bi(polyarene) unit tethered to the boron center through oxygen atoms constitute an interesting family of O-BODIPYs, useful for the development of photonic applications, such as structurally-simple EET molecular cassettes (arene-BODIPY dyads), as well as sources of circularly polarized light [16e,17b] including circularly polarized laser [18], field that has arisen as one of the most interesting and emerging topics dealing with BODIPYs $[9,19]$. This is due to three main factors: (1) synthetic accessibility leading to the development of low-cost dyes $[17 \mathrm{~b}, 20]$, (2) tunable photonic properties by straightforward chemical transformations [20] and (3) chiral perturbation to the BODIPY chromophore, when a chiral polyarene is used [17b]. This efficient chiral perturbation has been demonstrated by the workability of this structure as a new structural design for CPL-SOMs [17b]. The chiroptical behavior is a consequence of the chiral perturbation over the inherently achiral BODIPY chromophore, exerted by the BINOL-based unit tethered to it in an orthogonal spiranic fashion (e.g. 1a in Figure 1).

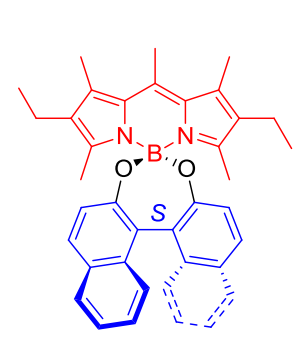

(S)-1a

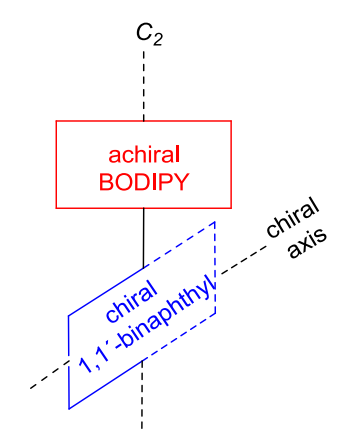

Figure 1. Example of bi(polyarene)-based O-BODIPY described by de la Moya as an efficient CPL-SOM.

In a previous study on the photophysical properties of a family of bi(polyarene)-derived $\mathrm{O}$-BODIPYs, we reported the possibility of promoting a non-emissive intramolecular charge transfer 
(ICT) state, which can be efficiently modulated by the substitution pattern, either at the dipyrrin core or at the polyarene moiety [20]. This result prompted us to hypothesize on the possibility of tuning chiroptical properties in this family of O-BODIPYs, as well, by tuning the said ICT. This proceeding presents the preliminary results on the chiroptical behavior (CD) of a selected family of bi(polyarene)-based spiranic O-BODIPYs.

\section{Results}

For this preliminary study, the small battery of chiral bi(polyarene)-derived O-BODIPYs shown in Figure 2 has been selected. With the aim of evaluating the relationship between dye structure and CD signalization, we chose a set of dyes covering different stereoelectronic effects on both dipyrrin core and bi(polyarene). On the one hand, dipyrrins with different degree of alkylation ( $c f .1$ and 2), aryl groups with free or restricted rotation ( $c f .2$ and 4 ) or electron withdrawing groups (EWG) in different positions (e.g. 3 and 5) were selected. On the other hand, a naked binaphtyl unit (a), or a bromine- or bis-3,5-(trifluoromethyl)phenyl-substituted binaphtyl unit (b and $\mathbf{c}$, respectively), or a $\pi$-extended biarene ( $\mathbf{d}$ and $\mathbf{e})$, were also selected. These structural variations led to significant differences in the photophysical behavior of the dyes, mainly due to ICT modulation [20], so they are expected to induce differences in the CD or CPL behavior, as well.

$O$-BODIPYs 1-5 were prepared following the previously described procedure [20], but using the corresponding enantiopure commercially available BINOL, BINOL derivative, VANOL or VAPOL, by nucleophilic substitution of fluorine in parent $F$-BODIPY promoted by $\mathrm{AlCl}_{3}$.
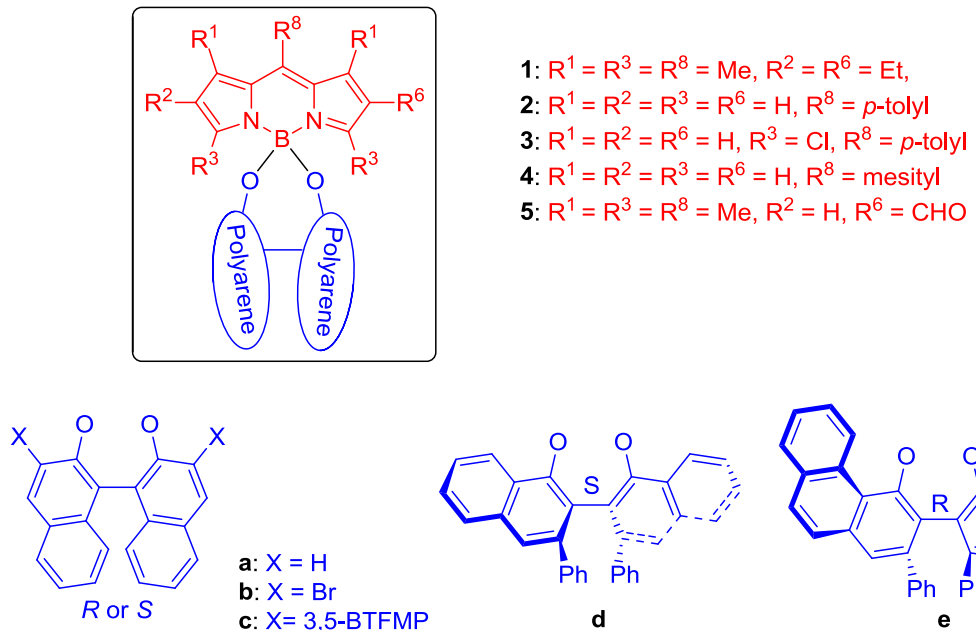

a: $X=\mathrm{H}$

b: $X=3,5-B T F M P$
c $X=B r$

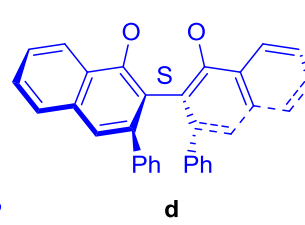

d

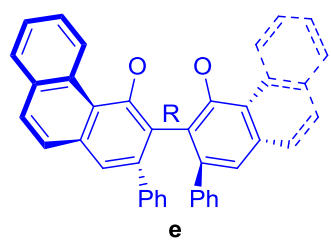

e

Figure 2. O-BODIPYs selected for the conducted study. $p$-tolyl $=p$-methylphenyl; mesityl $=$ 2,4,6-trimethylphenyl; 3,5-BTFMP = 3,5-bis(trifluoromethyl)phenyl.

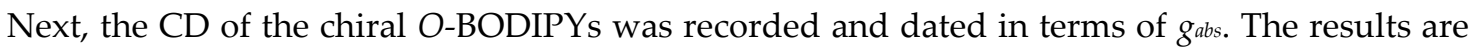
shown in Table 1. As expected, all the dyes are CD-active, with $\left|g_{a b s}\right|$ falling within the usual range for SOMs $\left(10^{-5}-10^{-3}\right)$.

All the BINOL-derived dyes (1a, 1b, 1c, 2a, 3a, 4a and 5a) show comparable $g_{a b s}$ values (around $\left.10^{-3}\right)$, negative for $O$-BODIPYs based on $(R)$-BINOL and positive for the $(S)$ enantiomers, with the exception of 1c, whose $C D$ response is significantly lower than in the other members of the series. On the contrary, the highest value for $g_{a b s}$ is found for $\mathbf{2 a}$. Regarding the dyes based on VANOL (4a) or VAPOL (5a), the sign tendency is maintained (negative for $R$ biaryl and positive for $S$ ). However, their absolute $g_{a b s}$ values are rather different. The structures differ only in a fused benzene ring, which makes the VAPOL unit to be bigger than the VANOL unit. It might be possible that a too high sterical hindrance has a negative effect on the helicity and, therefore, on the CD of the dye. This might be the reason for 1c having the lowest gabs value, given the size of its naphtyl-based substituents. 
Table 1. Kuhn's disymmetry ratio $\left(g_{a b s}\right)$ for studied O-BODIPYs (10-6 $\mathrm{M} \mathrm{CHCl}_{3}$ solution).

\begin{tabular}{|c|c|c|c|c|c|}
\hline Compound & $\lambda_{\text {abs }}(\mathrm{nm})$ & $10^{-4} \cdot \varepsilon\left(\mathrm{M}^{-1} \mathrm{~cm}^{-1}\right)$ & $\lambda_{\mathrm{fl}}(\mathrm{nm})$ & $\phi$ & $10^{3} \cdot g_{a b s}$ \\
\hline$(R)-1 a$ & 525 & 5.8 & 560 & 0.47 & -0.80 \\
\hline$(S)-1 \mathbf{a}$ & 525 & 6.0 & 560 & 0.47 & +0.75 \\
\hline$(R)-1 b$ & 527 & 7.4 & 547 & 0.69 & -0.86 \\
\hline$(S)-\mathbf{1 b}$ & 525 & 7.4 & 547 & 0.69 & +0.97 \\
\hline$(R)-1 \mathrm{c}$ & 524 & 7.2 & 548 & 0.82 & -0.10 \\
\hline$(S)-1 \mathrm{~d}$ & 527 & 5.6 & 557 & 0.11 & +1.30 \\
\hline$(R)-1 \mathrm{e}$ & 530 & 5.2 & 553 & 0.53 & -0.60 \\
\hline$(S)-2 \mathbf{a}$ & 504 & 4.4 & 536 & 0.017 & +1.40 \\
\hline$(S)-3 \mathbf{a}$ & 515 & 7.2 & 532 & 0.001 & +1.10 \\
\hline$(S)-4 a$ & 505 & 4.4 & 525 & 0.006 & +0.80 \\
\hline$(S)-5 \mathbf{a}$ & 497 & 5.2 & 515 & 0.021 & +0.75 \\
\hline
\end{tabular}

Unfortunately, no clear conclusions on the relationship between dye structure and CD behavior (level and sign) are extracted from these series. Nonetheless, it seems that the absolute $g_{a b s}$ value is increased significantly when ICT is acting significantly, as shown by poor fluorescence efficiency. However, this hypothesis should be assessed by further studies involving additional dyes with selected functional pattern modulating the ICT.

\section{Conclusions}

The interest of $\mathrm{CD}$ (e.g., in high-resolution and chiral sensing) makes it interesting to carry on studies on its modulation with the structure of the dye. Thus, the CDs of a series of chiral bi(polyarene) O-BODIPYs have been measured, all of them being CD-active. The found $g_{a b s}$ values fall within the typical range of most of the CD-active dyes based on SOM. Nonetheless, further investigation related with assessing the influence of the O-BODIPY structure in the dichroic signalization (level and sign) is needed to make possible the rational design of future chiral $O$-BODIPYs. Is this line, research is being conducted by synthesizing and chiroptically studying (CD and CPL) new series of chiral O-BODIPYs.

Acknowledgments: Financial support from Spanish MICINN (MAT2014-51937-C3-2-P) and MAT2015-68837-REDT).

Author Contributions: S.M. conceived the work; S.M. and B.L.M. designed general experiments and supervised the overall work; J.J. and E.M.S.-C. performed the synthetic developments of the dyes; F.M. designed the $\mathrm{CD}$ experiments; F.M., A.R.A. and M.J.O. carried out the $\mathrm{CD}$ measurements and analyzed the data; B.L.M., S.M. and J.J. wrote the paper.

Conflicts of Interest: The authors declare no conflict of interest.

\section{References}

1. Brittain, H.G. Excited-state optical activity, 1987-1995. Chirality 1996, 8, 357, DOI: 10.1002/(SICI)1520-636X(1996)8:5<357::AID-CHIR1>3.0.CO;2-B (b) Riehl, J.P.; Richardson, F.S. Circularly polarized luminescence spectroscopy, Chem. Rev. 1986, 86, 1, DOI: 10.1021/cr00071a001 (c) Comprehensive Chiroptical Spectroscopy Vol. 1. Instrumentation, Methodologies, and Theoretical Simulations (Eds.: Berova, N.; Polavarapu, P.L.; Nakanishi, K.; Woody, R.W.), John Wiley and Sons, Hoboken, 2012, ISBN: 9781118012932 (d) Luminescence of Lanthanide ions in Coordination Compounds and Nanomaterials (Ed.: de Bettencourt-Dias, A.), John Wiley and Sons, Chichester, 2014, ISBN: 978-1-119-95083-7.

2. (a) Canary, J. W.; Dai, Z.; Mortezaci, S. Spectroscopic Analysis: Chiropctical Sensors, in Comprehensive Chirality, ed. Carreira, E. M.; Yamamoto, H.; Elsevier, Amsterdam, 2012, 8, 600, DOI: 10.1016/B978-0-08-095167-6.00850-8. (b) Zsila, F. Electronic circular dichroism spectroscopy. In 
Pharmaceutical Sciences Encyclopedia 2010, 7, 1, DOI: 10.1002/9780470571224.pse405. (c) Berova, N.; Di Bari, L.; Pescitelli, G. Application of electronic circular dichroism in configurational and conformational analysis of organic compounds. Chem. Soc. Rev. 2007, 36, 914, DOI: 10.1039/b515476f. .

3. The degree of CD is given by the Kunh dissymmetry ratio, or absorption dissymmetry factor $g_{a b s}(\lambda)=2(\varepsilon \mathrm{L}-$ $\varepsilon \mathrm{R}) /(\varepsilon \mathrm{L}+\varepsilon \mathrm{R})$, where $\varepsilon \mathrm{L}$ and $\varepsilon \mathrm{R}$ are the molar absorption coefficients for left and right circularly polarized light, respectively.

4. The degree of CPL is given by the luminescence dissymmetry factor $g_{l u m}(\lambda)=2\left(I_{L}-I_{R}\right) /\left(I_{L}+I_{R}\right)$, where $I_{L}$ and $I_{R}$ are the intensities of left and right circularly polarized emission, respectively.

5. (a) Schadt, M. Liquid crystals materials and liquid crystals displays. Annu. Rev. Mater. Sci. 1997, 27, 305, DOI: 10.1146/annurev.matsci.27.1.305. (b) Wagenknecht, C.; Li, C.M.; Reingruber, A.; Bao, X.H.; Goebel, A.; Chen, Y.A.; Zhang, Q.; Chen, K.; Pan, J.W. Experimental demonstration of a heralded entanglement source. Nat. Photonics 2010, 4, 549, DOI: 10.1038/nphoton.2010.123. c) Sherson, J. F.; Krauter, H.; Olsson, R. K.; Julsgaard, B.; Hammerer, K.; Cirac, I.; Polzik, E. S. Quantum teleportation between light and matter. Nature 2006, 443, 557, DOI: 10.1038/nature05136. (d) Carr, R.; Evans, N. H.; Parker, D. Lanthanide complexes as chiral probes exploiting circularly polarized luminescence. Chem. Soc. Rev. 2012, 41, 7673, DOI: 10.1039/C2CS35242G. (e) Muller, G. Luminescent chiral lanthanide (III) complexes as potential molecular probes. Dalton Trans. 2009, 9692, DOI: 10.1039/B909430J. (f) Seitz, M.; Moore, E. G.; Ingram, A. J.; Muller, G.; Raymond, K. N. Circularly polarized luminescence in enantiopure europium and terbium complexes with modular, all-oxygen donor ligands. J. Am. Chem. Soc. 2007, 129, 15468, DOI: 10.1021/ic901079s. (g) Cave, R. Chemistry. Inducing chirality with circularly polarized light. J. Science 2009, 323, 1435, DOI: 10.1126/science.1169338. (h) Tsumatori, H.; Harada, T.; Yuasa, J.; Hasegawa, Y.; Kawai, T. Circularly Polarized Light from Chiral Lanthanide (III) Complexes in Single Crystals Appl. Phys. Express 2011, 4, 011601, DOI: 10.1143/APEX.4.011601.

6. (a) Heffern, M. C.; Matosziuk, L. M.; Meade, T. J. Lanthanide probes for bioresponsive imaging. Chem. Rev. 2014, 114, 4494, DOI: 10.1021/cr400477t. (b) Lunkley, J. L.; Shirotani, D.; Yamanari, K.; Kaizaki, S.; Muller, G. Extraordinary circularly polarized luminescence activity exhibited by cesium tetrakis(3-heptafluoro-butylryl-(+)-camphorato) $\mathrm{Eu}(\mathrm{III})$ complexes in $\mathrm{EtOH}$ and $\mathrm{CHCl}_{3}$ solutions. J. Am. Chem. Soc. 2008, 130, 13814, DOI: 10.1021/ja805681w.

7. (a) Inouye, M.; Hayashi, K.; Yonenaga, Y.; Itou, T.; Fujimoto, K.; Uchida, T.; Iwamura, M.; Nozaki, K. A doubly alkynylpyrene-threaded [4]rotaxane that exhibits strong circularly polarized luminescence from the spatially restricted excimer. Angew. Chem. Int. Ed. 2014, 53, 14392, DOI: 10.1002/anie.201408193. (b) Nagata, Y.; Takagi, K.; Suginome, M. Solid Polymer Films Exhibiting Handedness-Switchable, Full-Color-Tunable Selective Reflection of Circularly Polarized Light. J. Am. Chem. Soc. 2014, 136, 9858, DOI: 10.1021/ja504808r. (c) San Jose, B.A.; Yan, J.; Akagi, K. Dynamic switching of the circularly polarized luminescence of disubstituted polyacetylene by selective transmission through a thermotropic chiral nematic liquid crystal. Angew. Chem. Int. Ed. 2014, 53, 10641, DOI: 10.1002/anie.201404250. (d) Jeong, S.M.; Ohtsuka, Y.; Ha, N.Y.; Takanishi, Y.; Ishikawa, K.; Takezoe, H.; Nichimura, S.; Suzaki, G. Highly circularly polarized electroluminescence from organic light-emitting diodes with wide-band reflective polymeric cholesteric liquid crystal films. Appl. Phys. Lett. 2007, 90, 211106, DOI: 10.1063/1.2741603.

8. (a) Oyama, H.; Nakano, K.; Harada, T.; Kuroda, R.; Naito, M.; Nobusawa, K.; Nozaki, K. Facile Synthetic Route to Highly Luminescent Sila[7]helicene. Org. Lett. 2013, 15, 2104, DOI: 10.1021/ol4005036. (b) Maeda, H.; Bando, Y.; Shimomura, K.; Yamada, I.; Naito, M.; Nobusawa, K.; Tsumatori, H.; Kawai, T. Chemical-Stimuli-Controllable circularly polarized luminescence from anion-responsive $\pi$-conjugated molecules. J. Am. Chem. Soc. 2011, 133, 9266, DOI: 10.1021/ja203206g. (c) Field, J. E.; Muller, G.; Riehl, J. P.; Venkataraman, D. Circularly polarized luminescence from bridged triarylamine helicenes. J. Am. Chem. Soc. 2003, 125, 11808, DOI: 10.1021/ja035626e. (d) Kawai, T.; Kawamura, K.; Tsumatori, H.; Ishikawa, M.; Naito, M.; Fujiki, M.; Nakashima, T. Circularly Polarized Luminescence of a Fluorescent Chiral Binaphtylene-Perylenebiscarboxydiimide Dimer. ChemPhysChem 2007, 8, 1465, DOI: 10.1002/cphc.200600747.

9. Sánchez-Carnerero, E. M.; Agarrabeitia, A. R.; Moreno, F.; Maroto, B. L.; Muller, G.; Ortiz, M. J.; de la Moya, S. Circularly polarized luminescence from simple organic molecules. Chem. Eur. J. 2015, 21, 13488. DOI: $10.1002 /$ chem.201501178.

10. Wolf, C.; Bentley, K.W. Chirality sensing using stereodynamic probes with distinct electronic circular dichroism output. Chem. Soc. Rev. 2013, 42, 5408. DOI: 10.1039/C3CS35498A. 
11. (a) Eerdun, C.; Hisanaga , S.; Setsune, J.-I. Single helicates of dipalladium (II) hexapyrroles: helicity induction and redox tuning of chiroptical properties Angew. Chem., Int. Ed. 2013, 52, 929, DOI: 10.1002/anie.201207113. (b) Fuentes, N.; Martin Lasanta, A.; Álvarez de Cienfuegos, L.; Robles,R.; Choquesillo-Lazarte, D.; García-Ruiz, J.M.; Martínez-Fernández, L.; Corral, I.; Ribagorda, M.; Mota, A.J.; Cárdenas, D.J.; Carreño, M.C.; Cuerva, J.M. Versatile Bottom-up Approach to Stapled $\pi$-Conjugated Helical Scaffolds: Synthesis and Chiroptical Properties of Cyclic o-Phenylene Ethynylene Oligomers. Angew. Chem., Int. Ed. 2013, 51, 13036, DOI: 10.1002/anie.201206259. (c) Suzuki, T.; Tamaoki, H.; Wada, K.; Katoono, R.; Nehira, T.; Kawai, H.; Fujiwara, K. Induced preference for axial chirality in a triarylmethylium o,o-dimer upon complexation with natural $\gamma$-cyclodextrin: strong ECD signaling and fixation of supramolecular chirality to molecular chirality. Chem. Commun. 2012, 48, 2812, DOI: 10.1039/c2cc17475h. (d) Haketa, Y.; Bando, Y.; Takaishi, K.; Uchiyama, M.; Muranaka, A.; Naito, M.; Shibaguchi, H.; Kawai, T.; Maeda, H. Asymmetric induction in the preparation of helical receptor-anion complexes: ion-pair formation with chiral cations. Angew. Chem., Int. Ed. 2012, 51, 7967, DOI: 10.1002/anie.201202196. (e) Suk, J.M.; Naidu, V.R.; Liu, X.; Lah, M.S.; Jeong, K.S. A foldamer-based chiroptical molecular switch that displays complete inversion of the helical sense upon anion binding. J. Am. Chem. Soc. 2011, 133, 13938, DOI: 10.1021/ja206546b. (f) Takaishi, K.; Kawamoto, M.; Tsubaki, K.; Furuyama, T.; Muranaka, A.; Uchiyama, M. Helical Chirality of Azobenzenes Induced by an Intramolecular Chiral Axis and Potential as Chiroptical Switches. Chem. Eur. J. 2011, 17, 1778, DOI: 10.1002/chem.201003087.

12. (a) Loudet, A.; Burgess, K. BODIPY Dyes and Their Derivatives: Syntheses and Spectroscopic Properties. Chem. Rev. 2007, 107, 4891, DOI: 10.1021/cr078381n. (b) Ulrich, G.; Ziessel, R.; Harriman, A. The chemistry of fluorescent BODIPY dyes: versatility unsurpassed. Angew. Chem., Int. Ed. 2008, 47, 1184, DOI: 10.1002/anie.200702070 (c) Arbeloa, F.L.; Bañuelos, J.; Martínez, V.; Arbeloa, T.; López-Arbeloa, I. A general overview on the photophysics of BODIPY dyes in liquid solutions and solid polymer matrices Trends Phys. Chem. 2008, 13, 101, DOI: 10.1002/chin.201046261. (d) Boens, N.; Leen, V.; Dehaen, W. Fluorescent indicators based on BODIPY. Chem. Soc. Rev. 2012, 41, 1130, DOI: 10.1039/c1cs15132k. (e) Kamkaew, A.; Lim, S.H.; Lee, H.B.; Kiew, L.V.; Chung, L.Y.; Burgess, K. BODIPY dyes in photodynamic therapy Chem. Soc. Rev. 2013, 42, 77, DOI: 10.1039/C2CS35216H (f) Bessette, A.; Hanan, G.S. Design, synthesis and photophysical studies of dipyrromethene-based materials: insights into their applications in organic photovoltaic devices. Chem. Soc. Rev. 2014, 43, 3342, DOI: 10.1039/C3CS60411J (g) Lu, H.; Mack, J.; Yang, Y.; Shen, Z. Structural modification strategies for the rational design of red/NIR region BODIPYs. Chem. Soc. Rev. 2014, 43, 4778, DOI: 10.1039/c4cs00030g

13. (a) Zheng, Q.; Xu, G.; Prasad, P.N. Conformationally restricted dipyrromethene boron difluoride (BODIPY) dyes: highly fluorescent, multicolored probes for cellular imaging. Chem. Eur. J. 2008, 14, 5812, DOI: 10.1002/chem.200800309. (b) Wu, L.; Loudet, A.; Barhoumi, R.; Burghardt, R.C.;Burgess, K. Fluorescent cassettes for monitoring three-component interactions in vitro and in living cells. J. Am. Chem. Soc. 2009, 131, 9156, DOI: 10.1021/ja9029413. (c) Bozdemir, O.A.; Guliyev, R.; Buyukcakir, O.; Selcuk, S.; Kolemen, G.; Gulseren, G.; Nalbantoglu, H.;Boyaci, H.; Akkaya, E.U. Selective manipulation of ICT and PET processes in styryl-BODIPY derivatives: Applications in molecular Llogic and fluorescence sensing of metal ions. J. Am. Chem. Soc. 2010, 132, 8029, DOI: 10.1021/ja1008163. (d) Fan, J.; Hu, H.; Zhan, P.; Peng, X. Energy transfer cassettes based on organic fluorophores: construction and applications in ratiometric sensing. Chem. Soc. Rev. 2013, 42, 29, DOI: 10.1039/C2CS35273G. (e) Xiao, Y.; Zhang, D.; Qian, X.; Costela, A.; García-Moreno, I.; Martín, V.; Pérez-Ojeda, M.E.; Bañuelos, J.; Gartzia-Rivero, L.; López-Arbeloa, I. Unprecedented laser action from energy transfer in multichromophoric BODIPY cassettes. Chem. Commun. 2011, 47, 11513, DOI: 10.1039/C1CC13874J (f) Durán-Sampedro, G.; Agarrabeitia, A.R.; Cerdán, L.; Pérez-Ojeda, M.E.; Costela, A.; García-Moreno, I.; Esnal, I.; Bañuelos, J.; López-Arbeloa, I.; Ortiz, M.J. Carboxylates versus Fluorines: Boosting the emission properties of commercial BODIPYs in liquid and solid media. Adv. Funct. Mater. 2013, 23, 4195, DOI: 10.1002/adfm.201300198 (g) Durán-Sampedro, G.; Esnal, I.; Agarrabeitia, A.R.; Bañuelos, J.; Cerdán, L.; García-Moreno, I.; Costela, A.; López-Arbeloa, I.; Ortiz, M.J. First highly efficient and photostable $E$ and $C$ derivatives of 4,4-Difluoro-4-bora-3a,4a-diaza-s-indacene (BODIPY) as dye lasers in the liquid phase, thin films, and solid-state rods. Chem. Eur. J. 2014, 20, 2646, DOI: 10.1002/chem.201303579

14. (a) Jagtap, K.K.; Shivran, N.; Mula, S.; Naik, D.B.; Sarkar, S.K.; Mukherjee, T.; Maity, D.K,; Ray, A.K. Change of Boron substitution improves the Lasing performance of BODIPY dyes: A mechanistic 
rationalisation. Chem. Eur. J., 2013, 19, 702, DOI: 10.1002/chem.201202699. (b) Manzano, H.; Esnal, I.; Marqués-Matesanz, T.; Bañuelos, J. López-Arbeloa, I.; Ortiz, M.J.; Cerdán, L.; Costela, A.; García-Moreno, I.; Chiara, J.L. Unprecedented J-aggregated dyes in pure organic solvents. Adv. Funct. Mater. 2016, 26, 2756, DOI: 10.1002/adfm.201505051

15. (a) Bura, T.; Ziessel, R. Water-Soluble Phosphonate-Substituted BODIPY Derivatives with Tunable Emission Channels. Org. Lett. 2011, 13, 3072, DOI: 10.1021/ol200969r (b) Fan, G.; Yang, L.; Chen, Z. Water-soluble BODIPY and aza-BODIPY dyes: synthetic progress and applications. Front. Chem. Sci. Eng. 2014, 8, 405, DOI: 10.1007/s11705-014-1445-7

16. (a) Harriman, A.; Izzet, G.; Ziessel, R. Rapid energy transfer in cascade-type BODIPY dyes, J. Am. Chem. Soc. 2006, 128, 10231, DOI: 10.1021/ja0631448 (b) Alamiry, M.A.H.; Harriman, A.; Mallon, L.J.; Ulrich, G.; Ziessel, R. Energy- and charge-transfer processes in a perylene-BODIPY-pyridine tripartite Array. Eur. J. Org. Chem. 2008, 16, 2774, DOI: 10.1002/ejoc.200800159 c) Kaloudi-Chantzea, A.; Karakostas, N.; Pitterl, F.; Raptopoulou, C.P.; Glezos, N.; Pistolis, G. Efficient supramolecular synthesis of a robust circular light-harvesting BODIPY-dye based array. Chem. Commun. 2012, 48, 12213, DOI: 10.1039/C2CC36825K (d) Brizet, B.; Eggenspiller, A.; Gros, C.P.; Barbe, J.M.; Goze, C.; Denat, F.; Harvey, P.D. B,B-Diporphyrinbenzyloxy-BODIPY dyes: Synthesis and antenna effect. J. Org. Chem. 2012, 77, 3646, DOI: 10.1021/jo3000833 (e) Sánchez-Carnerero, E.M.; Gartzia-Rivero, L.; Moreno, F.; Maroto, B.L.; Agarrabeitia, A.R.; Ortiz, M.J.; Bañuelos, J.; López-Arbeloa, I.; de la Moya, S. Spiranic BODIPYs: a ground-breaking design to improve the energy transfer in molecular cassettes. Chem. Commun. 2014, 50, 12765, DOI: 10.1039/C4CC05709K (f) Zhang, S.; Wang, Y.; Meng, F.; Dai, C.; Cheng, Y.; Zhu, C. Circularly polarized luminescence of AIE-active chiral O-BODIPYs induced via intramolecular energy transfer. Chem. Commun. 2015, 51, 9014, DOI: 10.1039/C5CC01994J.

17. (a) Haefele, A.; Zedde, C.; Retailleau, P.; Ulrich, G.; Ziessel, R. Boron asymmetry in a BODIPY derivative. Org. Lett. 2010, 12, 1672, DOI: 10.1021/ol100109j (b) Sánchez-Carnerero, E.M.; Moreno, F.; Maroto, B.L.; Agarrabeitia, A.R.; Ortiz, M.J.; Vo, B.G.; Muller, G.; de la Moya, S. Circularly polarized luminescence by visible-light absorption in a chiral O-BODIPY dye: Unprecedented design of CPL organic molecules from achiral chromophores. J. Am. Chem. Soc. 2014, 136, 3346, DOI: 10.1021/ja412294s (c) Alnoman, R.B; Rihn, S.; O'Connor, D.; Black, F.A.; Costello, B.; Waddell, P.G.; Clegg, W.; Peacock, R.D.; Herrebout, W.; Knigth, J.G.; Hall, M.J. Circularly polarized luminescence from helically chiral $\mathrm{N}, \mathrm{N}, \mathrm{O}, \mathrm{O}$-Boron-chelated dipyrromethenes. Chem. Eur. J. 2016, 22, 93, DOI: 10.1002/chem.201504484

18. Jiménez, J.; Cerdán, L.; Moreno, F.; Maroto, B.L.; García- Moreno, I.; Lunkley, J.L.; Muller, G.; de la Moya, S. Chiral organic dyes endowed with circularly polarized laser emission. J. Phys. Chem. C, 2017, 121, 5287. DOI: $10.1021 /$ acs.jpcc.7b00654.

19. (a) Brunel, J.M. BINOL: A versatile chiral reagent. Chem. Rev. 2005, 105, 857, DOI: 10.1021/cr0500479 (b) Wang, Y.; Li, Y.; Liu, S.; Li, F.; Zhu, C.; Li, S.; Cheng, Y. Regulating circularly polarized luminescence signals of chiral binaphthyl-based conjugated polymers by tuning dihedral angles of binaphthyl moieties. Macromolecules, 2016, 49, 5444, DOI: 10.1021/acs.macromol.6b00883. (c) Zhang, L.; Zhao, L.; Wang, K.; Jiang, J. Chiral benzo-fused Aza-BODIPYs with optical activity extending into the NIR range. Dyes Pigm. 2016, 134, 427, DOI: 10.1016/j.dyepig.2016.07.039. (d) Lu, H.;Mack, J.; Nyokong, T.; Kobayashi, N.; Shen, Z. Optically active BODIPYs. Coord. Chem. Rev. 2016, 318, 1, DOI: 10.1016/j.ccr.2016.03.015

20. Gartzia-Rivero, L.; Sánchez-Carnerero, E.M.; Jiménez, J.; Bañuelos, J.; Moreno, F.; Maroto, B.L.; López-Arbeloa, I.; de la Moya, S. Modulation of ICT probability in bi(polyarene)-based O-BODIPYs: towards the development of low-cost bright arene-BODIPY dyads. Dalton Trans. 2017, 46, 11830, DOI: 10.1039/C7DT01984J.

(C) 2017 by the authors. Submitted for possible open access publication under the terms and conditions of the Creative Commons Attribution (CC BY) license (http://creativecommons.org/licenses/by/4.0/). 